\title{
MudANÇAS METOdológICAS E DESAFIOS NA MEDIÇÃo DA LIBE RDADE DE INFORMAÇÃO. UMA ANÁLISE DOS ÍNDICES Repórteres Sem Fronteiras e Freedom House
}

\author{
Ruth de Frutos \& Diego Giannone
}

\begin{abstract}
Resumo
O artigo analisa os principais desafios metodológicos colocados pelos dois indicadores mais importantes para medir a liberdade de imprensa no mundo. Freedom House (FH) e Repórteres Sem Fronteiras (RSF) tornaram-se referência para estudos que vão além da liberdade de imprensa, e sua importância nos obriga a analisar os aspetos metodológicos que determinam essas metodologias e que são omitidos. Os resultados deste estudo, ao analisar-se a avaliação dos países latino-americanos nos índices RSF e FH, nos permitem determinar que esses instrumentos apresentam graves deficiências metodológicas que, embora se tenham tentado corrigir, continuam a ser fonte de inúmeras controvérsias, como a ausência de mecanismos de proteção dos jornalistas em seus instrumentos de medição.
\end{abstract}

Palavras-chave

Indicadores; liberdade de imprensa; Freedom House; metodologia, Repórteres Sem Fronteiras

\begin{abstract}
The article analyses the main methodological challenges of the two most important indicators in measuring freedom of the press around the world. Freedom House (FH) and Reporters Without Borders (RWB) have become references for studies that go beyond freedom of the press and their importance forces us to analyze what the methodological aspects are that determined these methodologies and which are omitted. The results of this study make it possible to determine that the indicators of Reporters Without Borders and Freedom House present serious methodological deficiencies that, although they have tried to correct, continue to be the source of numerous controversies, such as the absence of mechanisms to protect journalists in their measurement instruments.
\end{abstract}

KEYWORDS

Indicators; freedom of information; Freedom House; methodology; Reporters Without Borders

\section{INTRODUÇÃo}

Desde a década de 1980, houve um crescimento exponencial de índices destinados a medir o desempenho de um Estado. Questões como liberdade econômica, competitividade, ambiente de negócios, idoneidade creditícia, democracia, corrupção e transparência tornaram-se temas centrais de vários benchmarks globais produzidos por instituições internacionais, organizações governamentais e não-governamentais e atores privados. 
Entre esses fatores, a liberdade de informação tem sido - juntamente com a liberdade - o foco principal da Freedom House (FH), com a publicação anual do Índice de Liberdade de Imprensa (FPI). Por mais de vinte anos, este instrumento tem sido praticamente a única medida da liberdade de mídia global. Somente nos últimos anos foi criado um novo instrumento pelos Repórteres Sem Fronteiras (RSF): o Índice Mundial de Liberdade de Imprensa (WPFI). No entanto, como esses índices diferem? E como eles se parecem? Que concepção(ões) de liberdade de informação eles medem e promovem? E de que maneira o uso de um índice influencia nossa percepção do nível de liberdade de informação no mundo? O artigo pretende abordar essas questões, propondo uma análise profunda dos aspectos teóricos e metodológicos dos dois instrumentos e focalizando dois problemas específicos: a segurança dos profissionais de mídia e a maneira pela qual os dois instrumentos medem a liberdade de informação na América Latina.

A segurança dos jornalistas é uma das principais preocupações da Organização das Nações Unidas (ONU) nos últimos anos', mas é extremamente difícil de quantificar. De fato, as organizações que medem a liberdade de expressão e o direito à informação introduzem as agressões sofridas pelos jornalistas em seus indicadores de maneira difusa, priorizando a análise qualitativa e não quantitativa. Esta hipótese requer um estudo detalhado de dois dos principais instrumentos, o FPI e o WPFI.

A liberdade de imprensa e o desenvolvimento da mídia têm sido fonte de numerosos estudos em escala internacional (Unesco, 2017). No entanto, a academia tem mostrado um interesse irregular nas ferramentas de medição usadas para medir esses parâmetros (Becker, Vlad \& Nusser, 2007; Holtz-Bacha, 2011) e, especialmente, nos aspectos abordados metodologicamente nessas medições. Esta pesquisa analisa criticamente dois dos instrumentos de medição mais conhecidos, como os desenvolvidos pelos RSF e FH. Em particular, a presente investigação observa como os RSF e a $\mathrm{FH}$ analisam vários parâmetros, dentre os quais se inclui, por sua gravidade, a segurança dos jornalistas.

Quando os jornalistas são alvos, as sociedades como um todo também pagam o preço. O tipo de notícia que é silenciada - corrupção, conflitos de interesses, tráfico ilegal - é exatamente o tipo de informação que o público precisa saber. (Guterres², 2017)

Com base em estudos anteriores sobre a estrutura ideológica e conceitual desses indicadores (de Frutos, 2014; Giannone, 2014; Giannone \& de Frutos, 2016), optou-se

\footnotetext{
' Apenas para dar um exemplo, o Conselho de Segurança das Nações Unidas adotou oito resoluções sobre a segurança dos jornalistas. "Desde 2012, oito resoluções sobre a segurança de jornalistas foram aprovadas por vários órgãos da ONU. Juntos, eles fornecem uma estrutura para a promoção da segurança de jornalistas em nível global e, mais importante, em nível nacional e local. Quatro resoluções foram aprovadas pela AGNU, três pelo CDH, uma pelo CSNU e outra pela Unesco. Antes de 2012, apenas duas resoluções estavam focadas nessa questão em particular; um foi aprovado pela Unesco em 1997 e outro pela UNSC, em 2006. As resoluções estão disponíveis nas seis línguas oficiais da ONU: árabe, chinês, inglês, francês, russo e espanhol" (IFEX, 2017). Desde 2013, em 2 de novembro, é o Dia Internacional para acabar com a impunidade por crimes contra jornalistas.

2 Declaração do Secretário-Geral da ONU, António Guterres, em 2 de novembro de 2017, na resolução da Assembleia Geral das Nações Unidas, n 68/163, designada como o Dia Internacional da Erradicação da Impunidade por Crimes contra Jornalistas.
} 
por analisar a abordagem das metodologias dos indicadores dos RSF e FH em uma determinada região, como a América Latina. O objetivo desta pesquisa é o de detectar não só as mudanças na estrutura metodológica dessas classificações, mas também a forma como isso afeta os casos particulares das nações da região.

Cerca de 50 jornalistas foram mortos ou "desapareceram" por praticar sua profissão na América Latina, durante o século XXI. Desde 2000, as agressões não só diminuíram com o estabelecimento de novos sistemas democráticos, mas também se intensificaram em contextos nacionais complexos, caracterizados pela violência, pelas ações de múltiplos perpetradores e pela impunidade. Essa situação dramática tornou-se numa linha prioritária para organizações internacionais nos últimos anos (Badran, 2017; Hughes et al., 2017), especialmente desde a elaboração do Plano de Ação da ONU sobre Segurança dos Jornalistas e a questão da impunidade 3 (ONU, 2012).

Os objetivos de desenvolvimento sustentável, que compõem o Programa 2030 para o Desenvolvimento Sustentável, definiram a criação de medidas para "promover sociedades pacíficas e inclusivas para o desenvolvimento sustentável, fornecer acesso à justiça para todos e construir instituições eficazes, responsáveis e inclusivas em todos os níveis" (Meta 164), o que também destaca a proteção das liberdades fundamentais e o acesso público à informação. A segurança dos jornalistas e a eliminação da impunidade por violações de direitos humanos são componentes fundamentais para alcançar esses objetivos 5 .

\section{REVISÃO DE LITERATURA E ESTADO DA ARTE}

Vários estudos usam o FPI para suas análises. Alguns estudiosos usaram-no em esforços para identificar novas correlações entre liberdade de imprensa e democracia (Dahl, 2003), bem como para analisar o papel da imprensa livre na promoção da democratização, boa governança e desenvolvimento humano (Norris, 2006). Outros estudos utilizaram o FPI para testar a difusão da liberdade de mídia (Sobel, Dutta \& Roy, 2011), bem como a relação empírica entre direitos humanos e governança (Kaufmann, 2005), liberdade de imprensa e corrupção (Brunetti \& Weder 2003; Freille, Haque \& Kneller, 2007), liberdade de imprensa e paz democrática (Van Belle, 1997). As classificações e rankings do FPI figuram no debate político, em uma ampla gama de política externa, jornalismo e tomada de decisões de ajuda em todo o mundo. Pesquisadores do Banco Mundial os usaram na elaboração de documentos que ajudam a determinar a quantidade de ajuda que um país recebe. Agências da ONU e organizações de ajuda

\footnotetext{
3 O Plano de Ação da ONU para a Segurança dos Jornalistas e a questão da impunidade foi aprovado pelo Conselho Executivo da ONU em 12 de abril de 2012. O Plano foi preparado durante a $1^{a}$ Reunião Interagencial da ONU sobre esta questão, convocada pelo Diretor-Geral da Organização. Unesco a pedido do Conselho Intergovernamental do Programa Internacional para o Desenvolvimento da Comunicação (IPDC). Mais informações em http://www.unesco.org/new/en/ communication-and-information/freedom-of-expression/safety-of-journalists/un-plan-of-action/
}

${ }^{4}$ Mais informações em https://sustainabledevelopment.un.org/sdg16

5 Desenvolver ferramentas para medir a segurança dos jornalistas em resposta à 16.10.1 dos objetivos de desenvolvimento sustentável (SDG): "número de casos verificados de assassinato, seqüestro, desaparecimento forçado, detenção arbitrária e tortura de jornalistas, pessoal de mídia associado, sindicalistas e defensores dos direitos humanos nos últimos 12 meses". 
nacionais e privadas usam o índice na programação de centenas de milhões de dólares em financiamento para desenvolvimento de mídia. O FPI é uma das fontes do manual de boa governança do Programa das Nações Unidas para o Desenvolvimento (PNUD, 2004), bem como um dos indicadores usados pelo governo americano para determinar a elegibilidade do país para a assistência do programa Millennium Challenge Corporation (MCC) ${ }^{6}$. Repórteres e colunistas empregam-no em discursar sobre a liberdade de imprensa e diplomatas para pressionar os governos que estão em baixa no índice.

Estudos anteriores sobre o FPI incluem uma análise comparativa tanto dos avaliadores da liberdade de informação (Burgess, 2010), como dos instrumentos (Becker et al. 2007), bem como a possibilidade e utilidade de tais comparações globais (Holtz-Bacha, 2011). Algumas análises enfocaram a influência do uso de índices alternativos de liberdade de imprensa na determinação da relação entre desenvolvimento e liberdade de imprensa (Tran et al., 2011). Críticos do FPI sublinharam um dimensionamento incorreto e algumas dificuldades metodológicas (Becker, 2003). Além disso, FH é por vezes acusada de ter um preconceito pró-americano (Chomsky \& Herman, 1988; Giannone, 2010; ONU, 2001; Scoble \& Wiseberg, 1981). Por fim, uma análise aprofundada dos indicadores do FPI e sua interação com o neoliberalismo foi feita (Giannone, 2014), e as implicações políticas e ideológicas do uso deste instrumento foram enfatizadas.

Por seu lado, a análise dos Repórteres Sem Fronteiras tem sido utilizada por várias organizações não governamentais, como a Unesco, que elaborou um Guia de Segurança para Jornalistas: Um manual para repórteres em ambientes de alto risco em conjunto com a ONG (Unesco \& RSF, 2015). A pesquisa da própria organização tem sido utilizada por acadêmicos (Díaz Nosty, 2016a) para avaliar a situação da profissão de jornalista na América Latina, levando em conta o alto nível de impunidade nesses países. Por fim, as inúmeras mudanças metodológicas do RSF têm sido fonte de discussões acadêmicas (de Frutos, 2014; Díaz Nosty \& de Frutos, 2017; Sapiezynka \& Lagos, 2016), nas quais algumas controvérsias metodológicas foram destacadas.

\section{QUADRO TEÓRICO}

"Os meios de comunicação de massa são o tecido conectivo da democracia. Eles são o principal meio através do qual os cidadãos e seus representantes eleitos comunicam em seus esforços recíprocos para informar e influenciar" (Gunther \& Mughan, 2000, p. 1). No entanto, a literatura em ciência social e política é notável pela ausência quase geral de análises comparativas rigorosas da interação mutuamente influenciadora entre liberdade de informação, por um lado, e o caráter democrático básico dos regimes políticos, por outro (para uma exceção ver Voltmer, 2013).

O que é liberdade de informação? De acordo com Holtz-Bacha (2011, p. 130), "a liberdade de imprensa é entendida de forma diferente em várias partes do mundo" e

\footnotetext{
${ }^{6}$ A Corporação Desafio do Milênio é uma agência independente de ajuda externa dos EUA criada pelo Congresso dos Estados Unidos em 2004 com o objetivo de lutar contra a pobreza global, fornecendo ajuda externa aos países elegíveis. Para obter uma lista dos indicadores, consulte http://www.mcc.gov/pages/selection/indicators
} 
"mesmo as democracias estabelecidas não interpretam a liberdade de imprensa exatamente da mesma maneira".

As primeiras definições da liberdade de imprensa se concentraram principalmente na liberdade do controle governamental (Siebert et al. 1956). Essa perspectiva liberal clássica sobre a liberdade de mídia pode ser diferenciada da democrática radical.

Dentro da perspectiva liberal clássica (...) é uma "vertente" argumentando que a mídia deve servir para proteger o indivíduo dos abusos do Estado. Dentro da perspectiva da democracia radical (...) é uma "corrente" que argumenta que a mídia deve procurar corrigir os desequilíbrios na sociedade. (Becker et al., 2007, p. 6)

Essas duas definições dão origem a dois modelos diferentes de informação: o modelo liberal e o modelo de responsabilidade social7 (Hallin \& Mancini, 2012). Eles são tipos ideais, e os sistemas de mídia de países individuais só os ajustam de maneira grosseira. Cada modelo tem um ponto de vista avaliativo interno e atribui um papel diferente à liberdade de imprensa.

O modelo liberal de informação é caracterizado por uma relativa dominância de mecanismos de mercado e de mídia comercial. Este modelo distingue-se pela sua tendência a considerar a mídia como um empreendimento econômico e o mercado como a arena natural para o seu desenvolvimento. Essa compreensão clássica da informação tem sido fortemente influenciada pela ascensão do neoliberalismo e sua lembrança do ideal de um livre mercado de idéias (Mirowski, 2011). De acordo com este ideal, a diversidade se manifesta através da competição entre empresas e através da liberdade de escolha. A informação é, portanto, destinada a ser principalmente uma mercadoria. $O$ Mercado está encarregado de um mecanismo de regulação que deve garantir um equilíbrio econômico satisfatório entre a oferta e a demanda de informações. A liberdade de imprensa é tão mais garantida quanto menos o Estado intervém na regulação e controle do sistema midiático. De uma perspectiva neoliberal, de fato, a intervenção do Estado é considerada "predatória" (Banda, 2011, p. 97). Consequentemente, podemos obter uma preferência pela imprensa comercial e pela televisão, em detrimento daquelas orientadas por partidos ou controladas pelo Estado.

Por outro lado, o modelo de responsabilidade social vê a mídia como uma instituição social, com a tarefa de assegurar o acesso e a representação completa de pontos de vista diferentes, culturais e políticos (McQuail, 2000). A informação é concebida como um bem público, produzido na esfera pública e destinado a influenciar a formação da opinião pública e as decisões públicas. Portanto, estamos lidando com um direito democrático fundamental que deve garantir um modelo de democracia igualitária. O papel do Estado não é demonizado porque, para proteger a pluralidade e a diversidade de opiniões dentro do sistema de mercado, tanto a TV estatal quanto a comercial devem coexistir,

\footnotetext{
7 Hallin e Mancini (2012) definem-no como modelo corporativista democrático e identificam também um modelo pluralista-polarizado, que é uma mistura dos elementos dos outros dois modelos. Por essa razão, levamos em conta apenas os modelos corporativistas liberais e democráticos.
} 
são concedidos subsídios para a imprensa, assim como o direito de resposta e acesso a todos os grupos sociais (como minorias étnicas, religiosas, políticas e linguísticas).

\section{Metodologia}

O método utilizado para analisar os indicadores dos Repórteres sem Fronteiras e Freedom House tem sido uma análise documental, com especial atenção às modificações metodológicas ocorridas nos relatórios, questionários e índices utilizados por essas duas organizações.

O monitoramento e a descrição das mudanças, assim como as investigações derivadas desse tipo de indicadores, permitem traçar tendências na representação da liberdade de imprensa no mundo e no caso latino-americano em particular.

O estudo baseia-se na hipótese de que tanto a classificação da liberdade de imprensa dos RSF quanto a da FH penalizam o desempenho do Estado como garantidor dos direitos dos cidadãos em geral e dos jornalistas em particular. Assim, alguns países obtêm posições mais favoráveis que não têm que ver diretamente com a situação de liberdade de expressão dentro de suas fronteiras, mas com instrumentos que os beneficiam no ranking.

Diante dessa dificuldade na obtenção de dados e do relativamente baixo interesse acadêmico em uma questão tão relevante na configuração dos sistemas de mídia em democracia (Nações Unidas, 2017a, 2017b), é essencial definir estratégias metodológicas que possibilitem a visualização do estado de saúde da liberdade de imprensa na América Latina, a situação dos mecanismos de proteção dos jornalistas e a eficácia do esforço internacional para fornecer um aparato multilateral crítico aos processos de segurança dos profissionais da informação.

\section{RESULTADOS}

\section{Repórteres Sem Fronteiras}

Em 1985, a organização sem fins lucrativos Repórteres Sem Fronteiras foi fundada na França. Atualmente, é uma das organizações de liberdade de imprensa mais conhecidas do mundo. Entre seus projetos, destaca-se o World Press Freedom Index, um ranking internacional nascido em 2002 que classifica os países levando em conta diferentes variáveis.

RSF tem uma metodologia que mudou ao longo dos anos. Enquanto que em sua classificação de 2010 a organização enviou um questionário para cerca de 150 especialistas internacionais, os quais foram questionados sobre 43 questões, nos últimos anos este sistema mudou. Se nos detivermos na metodologia dessa classificação, as perguntas foram divididas em sete seções: 1. violência física, 2. número de jornalistas mortos, detidos, fisicamente atacados ou ameaçados, o papel das autoridades nesses casos, 3. sugestões de ameaças, assédio e acesso à informação, 4. censura e autocensura, 5. controle da mídia, 6. pressões judiciais, financeiras. 
No entanto, como afirmam Sapiezynska e Lagos (2016, p. 554), "nenhuma dessas seções incluiu perguntas sobre a estrutura de propriedade da mídia ou sobre sua concentração econômica em mãos privadas".

De fato, as questões na seção dedicada ao "controle da mídia" apenas questionavam a existência de empresas de mídia privadas e se elas eram "livres para determinar sua linha editorial". Nesse sentido, pode-se observar como os RSF priorizaram a avaliação das restrições do Estado à liberdade de expressão sobre as conseqüências da concentração midiática ou limitações editoriais em determinadas mídias privadas.

Além do cuidado excessivo com o controle estatal para garantir o livre mercado, chama-se a atenção para a referência à violência e ao número de jornalistas mortos, detidos ou agredidos fisicamente. Embora seja verdade que, no caso da América Latina, esse tipo de ameaça se deve a um cenário de violência estrutural, a realidade da região é muito diversificada e parece ter mais a ver com regimes ditatoriais ou fracassados do que com países democráticos.

Um ano depois, a metodologia dos RSF passou por uma forte modificação, incluindo mais respostas com pontos negativos, o que levou a uma mudança no resultado das mais bem posicionadas que ficaram abaixo de zero (como é o caso da Finlândia e da Noruega, com pontuações de -10).

Da mesma forma, a estrutura do mercado e a análise do pluralismo dos RSF refletem novamente uma clara atenção ao mercado livre sobre a posição de garantia do Estado: na questão 37: [há] ameaças sérias à diversidade midiática, sobretudo como resultado da propriedade da mídia ser concentrada em poucas mãos? Qual das seguintes afirmações se aplica melhor ao seu país? Coloque uma cruz ao lado da declaração que melhor corresponda à situação em seu país:

1. O pluralismo da mídia não está em perigo.

2. Existem algumas ameaças ou limitações ao pluralismo da mídia.

3. O pluralismo dos meios de comunicação existe, mas está seriamente ameaçado.

4. A propriedade da mídia está concentrada em poucas mãos e não há pluralismo. (RSF, 2012b, p. 7)

O problema que surge da presente análise é a quase total ausência de preocupação com as restrições à liberdade de informação - porque este é o conceito preferido por ambas as organizações - imposto pelo mercado. Se nos referirmos a ela em termos de responsabilidade estatal, está na ausência ou fraqueza de leis e políticas públicas para evitar as restrições derivadas do mercado. Mais uma vez, esta é uma área não coberta pelos questionários (Sapiezynska \& Lagos, 2016).

Finalmente, enfatiza que o RSF omite o papel dos cidadãos como um agente ativo ou passivo da comunicação. Embora se refiram à universalidade da liberdade de imprensa, ela é camuflada pelo mercado, sem a garantia dada por um modelo de responsabilidade social e nem mesmo por um modelo liberal de informação. A presença de um Estado constitucional democrático tem sido fortemente defendida não só pela ONU e pela 
Unesco, mas também pelo Escritório do Relator Especial para a Liberdade de Expressão da Comissão Ibero-Americana de Direitos Humanos.

A definição de valores de o a 100 foi usada no índice de 2013 e é mantida até hoje. Assim, os países mais bem posicionados são próximos de zero e os piores, próximos de 100. Questões relacionadas à segurança dos jornalistas e à questão da impunidade, bem como as ações judiciais decorrentes dessas, foram omitidas do questionário de especialistas e atualmente são os especialistas do RSF que são responsáveis por coletar esses dados. Portanto, observamos uma evolução no desenho metodológico que começa a se tornar sofisticado através da justaposição de instrumentos.

O questionário, por outro lado, consistia em 74 questões divididas em cinco seções temáticas: 1. Estado da mídia, 2. Estado dos jornalistas, 3. Pluralismo e independência editorial, 4. Lei e aplicação da lei e 5. Internet e recursos técnicos.

Para calcular os resultados, a RSF dividiu as perguntas novamente, desta vez em seis critérios, atribuindo aos países uma pontuação de o a 100 para cada um deles:

1. Pluralismo, "mede o grau em que diferentes opiniões são representadas no espaço da mídia" (Plu),

2. Independência da mídia, "mede a capacidade da mídia de funcionar independentemente dos poderes político, governamental, econômico e religioso" (Ind)

3. Ambiente e autocensura, "analisa as condições sob as quais as atividades de informação são realizadas" (EnA)

4. Enquadramento legal, "mede o desempenho do enquadramento legal que regula as atividades de infromação" (CL)

5. Transparência "mede a transparência das instituições e procedimentos que afetam a produção de informação" (Tra)

6. Infra-estrutura, "mede a qualidade da infra-estrutura com a qual a produção de informações ocorre" (Inf)

$\mathrm{Na}$ classificação de 2016, um sétimo indicador que se refere especificamente à segurança dos jornalistas no período considerado é incluído:

7. Assaltos, "Mede a intensidade da violência no período observado" (RSF, 2017) (Exa)

$$
S C O A=1 / 3 * P l u+1 / 6 *(\operatorname{Ind}+\operatorname{En} A+C L)+1 / 12 *(\operatorname{Tr} a+\operatorname{Inf})
$$

O segundo incorporando a taxa, dando-lhe um peso de $20 \%$ :

$$
S C O B=1 / 5 * E x a+4 / 15 * P l u+2 / 15 *(\operatorname{Ind}+\operatorname{En} A+C L)+1 / 15 *(\operatorname{Tr} a+\operatorname{Inf}) .
$$

Com relação ao cálculo do escore de agressão:

$S$ coreExa $=10 * \log \left(90 * n^{\circ}\right.$ killed + Coefficient $f_{i} * n^{\circ}$ prisoners $+10 n^{\circ}$ kidnapped $+5 *$ $n^{\circ}$ attacks on the media $+3 * n^{\circ}$ exiled $+n^{\circ}$ arrests $+n^{\circ}$ aggressions)

O coeficiente é calculado levando-se em conta que quanto mais tempo um jornalista é preso, mais responsabilidade será dada ao país responsável. Assim, o RSF calcula o coeficiente da seguinte maneira. 


\begin{tabular}{llllllllllll}
\hline 1 & $1-$ & 2 & 3 & 4 & 5 & 6 & 7 & 8 & 9 & 10 & +10 \\
\hline Coeficient fi & 10 & 20 & 35 & 60 & 80 & 85 & 87 & 88 & 89 & 89,5 & $\begin{array}{l}\text { Lim Coef } \\
\text { fi }=90\end{array}$ \\
\hline
\end{tabular}

Tabela 1: Cálculo do escore do coeficiente de agressão. Fonte: RSF (2017)

A pontuação final é determinada com a seguinte fórmula:

Pontuação final $=\max (\mathrm{scOA}, \mathrm{scOB})$,

isto é, selecionando a maior das duas pontuações como a pontuação final. Essas mudanças metodológicas influenciam irremediavelmente a classificação final e o valor no tempo de vários países latino-americanos. Apesar dessas mudanças, a classificação dos Repórteres Sem Fronteiras continua a beneficiar o papel do livre mercado para o Estado na garantia dos direitos de expressão e liberdade de informação dos cidadãos.

Esses tipos de problemas podem ser avaliados observando-se os últimos anos da classificação global da RSF.

Dos dezenove países analisados na América Latina (180 no total) para este estudo, a RSF coloca a grande maioria na segunda metade da tabela da sua classificação de 2017: Bolívia (107, pontuação: 33,58), Brasil (103, pontuação:33.58), Colômbia (129, placar: 41,47), Cuba (173, placar: 71,75), Equador (105, placar: 33,64), Guatemala (118, placar: 39,33), Honduras (140, pontuação: 43,75), México (147, placar: 48,97), Nicarágua (92, placar: 31,01), Panamá (96, placar: 32,12), Paraguai (110, placar: 35, 64), Peru (90, pontuação: 30,98) e Venezuela (137, pontuação: 42,94). Apenas Costa Rica (6, placar: 11,93), Uruguai (25, placar: 17,43), Chile (33, placar: 20,53), Argentina (50, placar: 25,07), República Dominicana (59, pontuação: 26,76$)$ e El Salvador (62, pontuação: 27,24) estavam em posições superiores (Tabela 2 ).

\begin{tabular}{lll}
\hline & PoNTUAÇÃo & Posição \\
\hline Argentina & 50 & 25,07 \\
\hline Bolivia & 107 & 33,58 \\
\hline Brasil & 103 & 33,58 \\
\hline Chile & 33 & 42,94 \\
\hline Colômbia & 129 & 41,47 \\
\hline Costa Rica & 6 & 11,93 \\
\hline Cuba & 173 & 71,75 \\
\hline Equador & 105 & 33,64 \\
\hline El Salvador & 62 & 27,24 \\
\hline Guatemala & 118 & 39,33 \\
\hline Honduras & 140 & 43,75 \\
\hline México & 147 & 48,97 \\
\hline
\end{tabular}




\begin{tabular}{lll}
\hline Nicarágua & 92 & 31,01 \\
\cline { 2 - 4 } Panamá & 96 & 32,12 \\
\hline Paraguai & 110 & 35,64 \\
\cline { 2 - 4 } Peru & 90 & 30,98 \\
\hline Republica Domincana & 59 & 26,76 \\
\hline Uruguai & 25 & 17,43 \\
\hline Venezuela & 137 & 42,94
\end{tabular}

Tabela 2: 2017 World Press Freedom Index. Tabela de posições e pontuações do país da América Latina Fonte: RSF, 2017

Porém, lembre-se que esses países têm uma grande diferenciação entre eles e com situações críticas em algumas nações determinadas pela multiplicidade de perpetradores, a insegurança dos profissionais da informação e um cenário de permanente impunidade que perpetua essas condições de vulnerabilidade. México, Colômbia, Honduras, Brasil e Guatemala são os países mais perigosos para a prática profissional durante os primeiros 17 anos do século XXI.

Para citar o exemplo mais extremo, o México se perpetua como o país mais perigoso para exercer o jornalismo na região (González de Bustamante \& Relly 2017, 2016; Hughes e Márquez Ramírez, 2017), com 163 jornalistas mortos nesses 17 anos, além a outros tipos de violência, e na classificação da RSF aparece à frente de outros países da região, como Cuba, onde não houve morte.

Desde 2006, o número de profissionais da informação assassinados no México aumentou consideravelmente, coincidindo com a luta contra o narcotráfico (Relly \& González de Bustamante, 2014, 2017). A criação da Procuradoria Especial para a Atenção aos Crimes contra a Liberdade de Expressão (FEADLE, em espanhol) e em 2012 de um mecanismo de proteção para defensores e jornalistas de direitos humanos não melhorou essa situação. De fato, várias organizações denunciaram que "não é prestada assistência efetiva aos jornalistas em situação de risco" e exigem que "a prevenção seja fortalecida para evitar os ataques letais" (CP), 2017, p. 37).

Com 57 vítimas, o Brasil é o quarto país com o maior número de jornalistas assassinados na América Latina. Mudanças políticas nos últimos anos e protestos de cidadãos têm sido amplamente abordados nos meios de comunicação públicos, privados e comunitários, aumentando a vulnerabilidade dos profissionais da informação. $O$ ano de 2015 foi particularmente digno de nota, pois nove profissionais da informação morreram. Repórteres Sem Fronteiras promoveu a campanha durante os Jogos Olímpicos de 2016, chamada "algumas vitórias não merecem uma medalha", na qual denunciou os casos de jornalistas brasileiros mortos no exercício de seu trabalho profissional. Entre eles, a RSF lembrou Gleydson Carvalho, jornalista morto quando pessoas desconhecidas o mataram nos estúdios da Rádio Libertade FM 90.3, em Camocim, no estado do Ceará, em 6 de agosto de 2015. Outro caso destacado nesta campanha é o da o jornalista 
Pedro Palma, diretor do semanário Panorama Regional, assassinado em sua casa em 13 de fevereiro de 2014 por ter denunciado casos de corrupção de funcionários no Rio de Janeiro (Díaz Nosty \& de Frutos, 2017).

\section{FREEDOM House}

A avaliação da metodologia da Freedom House, organização nascida nos Estados Unidos em 1941, permitiu identificar inconsistências claras entre as opiniões da organização e a aplicação dos indicadores. A FH refere-se ao artigo 19 da Declaração Universal dos Direitos Humanos que afirma que "todos têm o direito à liberdade de opinião e expressão". Portanto, teoricamente, a liberdade de informação é concebida como um direito humano básico que todo estado deve proteger. No entanto, o processo de mensuração da SF não responde à universalidade do direito humano e ao Estado como garantidor dessa universalidade, mas se refere a ele como um direito individual, principalmente enquadrado em termos econômicos.

A Freedom House classifica os países em três categorias principais, levando em conta uma escala que varia desde a melhor pontuação (0) até a pior (100), com base em 23 perguntas e 109 indicadores divididos em três grandes categorias: ambiente legal, ambiente político e o ambiente econômico.

A metodologia da Freedom House, longe de avaliar a liberdade de expressão, concentra-se na liberdade de imprensa e mais ainda na liberdade dos proprietários privados de mídia, em detrimento dos direitos dos jornalistas e ignorando os cidadãos, titulares do direito à liberdade de expressão. Seu questionário procura descobrir, em primeiro lugar, até que ponto os estados "interferem" na liberdade das empresas de mídia privadas e, em segundo lugar, os ataques físicos e as restrições legais e governamentais contra jornalistas. Restrições à liberdade de expressão, informação ou comunicação na mídia por atores privados - e não apenas o estado - estão incluídas, mas minimamente e com escasso peso na metodologia. (Sapiezynska \& Lagos, 2016, p. 564)

Como já foi demonstrado em um estudo anterior (Giannone, 2014), a partir do nascimento do instrumento em 1979, uma série de importantes mudanças metodológicas foram feitas no Freedom of the Press Index. Em 1994, uma escala de 100 pontos foi introduzida, juntando-se ao sistema de rotulagem preexistente (países de imprensa "livres", "parcialmente livres", "não livres"). Enquanto o último apenas permitiu dividir os países em três categorias, o sistema de classificação trouxe para a criação de classificações globais anuais de liberdade de informação, permitindo a comparabilidade dos países dentro de cada categoria e constituindo uma pressão para os países melhorarem seu desempenho. Outra mudança metodológica foi introduzida em 1989. Até 1988, o instrumento fornecia dois índices distintos de liberdade, um para a imprensa e outro diferente para o sistema de rádio-TV. Os dois sistemas foram unificados de 1989 a 1993. 
Então, de 1994 a 2001, após a introdução do sistema de pontuação, o FPI forneceu uma pontuação total e oito sub-pontuações (quatro para a impressão e quatro para transmissão), referentes respectivamente à ambiente jurídico, político e econômico, e ações repressivas $^{8}$. Como Karlekar Deutsch e Radsch apontaram (2012, p. 15), a metodologia foi "substancialmente renovada" em 2002. Em primeiro lugar, a distinção entre impressão e transmissão foi excluída novamente. Em segundo lugar, a categoria de ações repressivas foi eliminada, e sua pontuação foi atribuída à categoria de "ambiente político", sendo responsável por 40 dos 100 pontos alocados na metodologia da pesquisa. Essa mudança foi justificada pelo fato de que controlar o poder de enquadrar mensagens como notícias "tem sido a política de governos repressivos desde a introdução da radiodifusão” (Karlekar Deutsch \& Radsch, 2012, p. 15). Como o 'ambiente político' se preocupa com o papel do governo na apropriação, regulação e controle dos sistemas midiáticos, "a FH assume que tal papel é mais importante que o papel das corporações privadas (o ambiente econômico, pontuado até 30 pontos) ) ou disposições legais (até 30 pontos) para influenciar a liberdade de informação" (Giannone, 2014, p. 517).

Nos últimos anos, o questionário da organização dos EUA sofreu "pequenas, mas significativas mudanças". Para citar alguns dos mais característicos, a partir de 2011 , a palavra blogueiros foi introduzida em algumas das questões, juntamente com jornalistas profissionais. As instruções para responder a outra pergunta indicam que o entrevistado deve "considerar mídia escrita, audiovisual e internet". A Freedom House incluiu essas mudanças em resposta às críticas ao foco exclusivo na mídia tradicional e ao desdém pelos meios digitais (Burgess, 2010). Apesar dessas mudanças, a FH continua a apoiar a possibilidade de comparar os dados cobrindo todo o período de referência (Freedom House, 2012).

No que diz respeito à segurança dos profissionais de mídia, o FPI contém duas questões de metodologia dedicadas a essa questão, ambas incluídas na categoria "ambiente político". O primeiro deles, variando de o a 6 pontos, é: "os jornalistas locais e estrangeiros são capazes de cobrir as notícias de forma livre e segura em termos de acesso físico e relatórios em campo?". A segunda pergunta, variando de o a 10 pontos, é "os jornalistas, blogueiros ou meios de comunicação estão sujeitos a intimidação extralegal ou violência física por parte das autoridades estaduais ou de qualquer outro ator como resultado de sua denúncia?". Assim, o peso da segurança dos jornalistas no instrumento é de $16 \%$. Ambas as perguntas são combinadas com uma nota, introduzida na última edição do instrumento, que especifica que "a pergunta se aplica a condições vivenciadas por jornalistas, blogueiros ou meios de comunicação durante o curso de seu trabalho" (Freedom House, 2017a). No entanto, esta é apenas a última versão das perguntas. Como mostrado por uma análise longitudinal (ver Tabela 3), de 2009 até hoje estas duas questões, e seus indicadores, sofreram várias mudanças.

\footnotetext{
${ }^{8}$ Para dados detalhados (1980-2017) e mudanças nas sub-pontuações no período 1994-2001, consulte https://freedomhouse.org/sites/default/files/FOTP1980-FOTP2017_Public-Data.xlsx
} 


\begin{tabular}{|c|c|c|c|c|}
\hline & 2009 & 2013 & 2016 & 2017 \\
\hline Pergunta $n^{\circ} 6$ & $\begin{array}{l}\text { Os jornalistas locais } \\
\text { e estrangeiros são } \\
\text { capazes de cobrir as } \\
\text { notícias livremente? }\end{array}$ & $\begin{array}{l}\text { Os jornalistas locais } \\
\text { e estrangeiros podem } \\
\text { cobrir as notícias livre- } \\
\text { mente em termos de } \\
\text { assédio e acesso físico? }\end{array}$ & $\begin{array}{l}\text { Os jornalistas locais e } \\
\text { estrangeiros podem cobrir } \\
\text { as notícias de maneira livre e } \\
\text { segura em termos de acesso } \\
\text { físico e relatórios locais? }\end{array}$ & $\begin{array}{l}\text { Os jornalistas locais e } \\
\text { estrangeiros podem cobrir } \\
\text { as notícias de maneira livre e } \\
\text { segura em termos de acesso } \\
\text { físico e relatórios locais? }\end{array}$ \\
\hline \multirow[t]{8}{*}{$\begin{array}{l}\text { Indicadores da } \\
\text { questão } n^{\circ} 6\end{array}$} & $\begin{array}{l}\text { Os jornalistas são } \\
\text { assediados enquanto } \\
\text { cobrem as notícias? }\end{array}$ & $\begin{array}{l}\text { Os jornalistas são } \\
\text { assediados enquanto } \\
\text { cobrem as notícias? }\end{array}$ & $\begin{array}{l}\text { Até que ponto os jorna- } \\
\text { listas são perseguidos ou } \\
\text { atacados enquanto tentam } \\
\text { reunir notícias ou cobrir } \\
\text { eventos pessoalmente? }\end{array}$ & $\begin{array}{l}\text { Até que ponto os jorna- } \\
\text { listas são perseguidos ou } \\
\text { atacados enquanto tentam } \\
\text { reunir notícias ou cobrir } \\
\text { eventos pessoalmente? }\end{array}$ \\
\hline & $\begin{array}{l}\text { Algumas áreas } \\
\text { geográficas do país } \\
\text { estão fora dos limites } \\
\text { dos jornalistas? }\end{array}$ & $\begin{array}{l}\text { Algumas áreas } \\
\text { geográficas do país } \\
\text { estão fora dos limites } \\
\text { dos jornalistas? }\end{array}$ & $\begin{array}{l}\text { Algumas áreas geográfi- } \\
\text { cas do país estão fora dos } \\
\text { limites dos jornalistas? }\end{array}$ & $\begin{array}{l}\text { Algumas áreas geográfi- } \\
\text { cas do país estão fora dos } \\
\text { limites dos jornalistas? }\end{array}$ \\
\hline & $\begin{array}{l}\text { Será que uma guerra, } \\
\text { insurreição ou situação } \\
\text { semelhante em um } \\
\text { país inibe o funcio- } \\
\text { namento da mídia? }\end{array}$ & $\begin{array}{l}\text { Será que uma guerra, } \\
\text { insurreição ou situação } \\
\text { semelhante em um } \\
\text { país inibe o funcio- } \\
\text { namento da mídia? }\end{array}$ & $\begin{array}{l}\text { Será que uma guerra, insur- } \\
\text { reição ou situação seme- } \\
\text { lhante em um país inibe o } \\
\text { funcionamento da mídia? }\end{array}$ & $\begin{array}{l}\text { Será que uma guerra, } \\
\text { insurreição ou situação } \\
\text { semelhante em um país inibe } \\
\text { o funcionamento da mídia? }\end{array}$ \\
\hline & & & $\begin{array}{l}\text { As autoridades exigem que } \\
\text { os jornalistas que trabalham } \\
\text { em zonas de perigo sejam } \\
\text { "incorporados (embedded)"? }\end{array}$ & $\begin{array}{l}\text { As autoridades exigem que } \\
\text { os jornalistas que trabalham } \\
\text { em zonas de perigo sejam } \\
\text { "incorporados (embedded)"? }\end{array}$ \\
\hline & $\begin{array}{l}\text { Existe vigilância de } \\
\text { jornalistas estrangeiros } \\
\text { que trabalham no país? }\end{array}$ & $\begin{array}{l}\text { Existe vigilância de } \\
\text { jornalistas estrangeiros } \\
\text { que trabalham no país? }\end{array}$ & $\begin{array}{l}\text { Existe vigilância de } \\
\text { jornalistas estrangeiros } \\
\text { que trabalham no país? }\end{array}$ & $\begin{array}{l}\text { Existe vigilância de } \\
\text { jornalistas estrangeiros } \\
\text { que trabalham no país? }\end{array}$ \\
\hline & $\begin{array}{l}\text { Os jornalistas estran- } \\
\text { geiros são inibidos } \\
\text { ou barrados pela } \\
\text { necessidade de garantir } \\
\text { vistos ou autorizações } \\
\text { para reportar ou viajar } \\
\text { dentro do país? }\end{array}$ & $\begin{array}{l}\text { Os jornalistas estran- } \\
\text { geiros são inibidos } \\
\text { ou barrados pela } \\
\text { necessidade de garantir } \\
\text { vistos ou autorizações } \\
\text { para reportar ou viajar } \\
\text { dentro do país? }\end{array}$ & $\begin{array}{l}\text { Os jornalistas estrangeiros } \\
\text { são inibidos ou barra- } \\
\text { dos pela necessidade de } \\
\text { garantir vistos ou autori- } \\
\text { zações para reportar ou } \\
\text { viajar dentro do país? }\end{array}$ & $\begin{array}{l}\text { Os jornalistas estrangeiros } \\
\text { são inibidos ou barra- } \\
\text { dos pela necessidade de } \\
\text { garantir vistos ou autori- } \\
\text { zações para reportar ou } \\
\text { viajar dentro do país? }\end{array}$ \\
\hline & $\begin{array}{l}\text { Os jornalistas estrangei- } \\
\text { ros são deportados por } \\
\text { reportagens que desa- } \\
\text { fiam o regime ou outros } \\
\text { interesses poderosos? }\end{array}$ & $\begin{array}{l}\text { Os jornalistas estran- } \\
\text { geiros são deportados } \\
\text { por reportagens que } \\
\text { desafiam o regime } \\
\text { ou outros interes- } \\
\text { ses poderosos? }\end{array}$ & $\begin{array}{l}\text { Os jornalistas estrangei- } \\
\text { ros são deportados por } \\
\text { reportagens que desa- } \\
\text { fiam o regime ou outros } \\
\text { interesses poderosos? }\end{array}$ & $\begin{array}{l}\text { Os jornalistas estrangei- } \\
\text { ros são deportados por } \\
\text { reportagens que desa- } \\
\text { fiam o regime ou outros } \\
\text { interesses poderosos? }\end{array}$ \\
\hline & 2009 & 2013 & 2016 & 2017 \\
\hline Pergunta $n^{\circ} 7$ & $\begin{array}{l}\text { Os jornalistas e meios } \\
\text { de comunicação estão } \\
\text { sujeitos a intimidação } \\
\text { extralegal ou violência } \\
\text { física por parte das au- } \\
\text { toridades estaduais ou } \\
\text { de qualquer outro ator? }\end{array}$ & $\begin{array}{l}\text { Os jornalistas e meios } \\
\text { de comunicação estão } \\
\text { sujeitos a intimidação } \\
\text { extralegal ou violência } \\
\text { física por parte das au- } \\
\text { toridades estaduais ou } \\
\text { de qualquer outro ator? }\end{array}$ & $\begin{array}{l}\text { Os jornalistas, blogueiros } \\
\text { ou meios de comunicação } \\
\text { estão sujeitos a intimidação } \\
\text { extralegal ou a violência } \\
\text { física por parte das auto- } \\
\text { ridades estaduais ou de } \\
\text { qualquer outro ator como } \\
\text { resultado de sua denúncia? }\end{array}$ & $\begin{array}{l}\text { Os jornalistas, blogueiros } \\
\text { ou meios de comunicação } \\
\text { estão sujeitos a intimidação } \\
\text { extralegal ou a violência física } \\
\text { por parte das autoridades } \\
\text { estaduais ou de qualquer } \\
\text { outro ator como resulta- } \\
\text { do de sua denúncia? }\end{array}$ \\
\hline $\begin{array}{l}\text { Indicadores da } \\
\text { questão } n^{\circ} 7\end{array}$ & $\begin{array}{l}\text { Os jornalistas estão } \\
\text { sujeitos a assassinatos, } \\
\text { ferimentos, assédio, } \\
\text { ameaças, seqües- } \\
\text { tros, expulsão, prisão } \\
\text { arbitrária e detenção } \\
\text { ilegal ou tortura? }\end{array}$ & $\begin{array}{l}\text { Os jornalistas estão } \\
\text { sujeitos a assassinatos, } \\
\text { ferimentos, assédio, } \\
\text { ameaças, seqües- } \\
\text { tros, expulsão, prisão } \\
\text { arbitrária e detenção } \\
\text { ilegal ou tortura? }\end{array}$ & $\begin{array}{l}\text { Os jornalistas ou blogueiros } \\
\text { estão sujeitos a assassina- } \\
\text { tos, ferimentos, assédio, } \\
\text { ameaças, seqüestros, } \\
\text { detenções arbitrárias e } \\
\text { detenções ilegais ou tortura } \\
\text { em retaliação por suas } \\
\text { atividades profissionais? }\end{array}$ & $\begin{array}{l}\text { Os jornalistas ou blogueiros } \\
\text { estão sujeitos a assassina- } \\
\text { tos, ferimentos, assédio, } \\
\text { ameaças, seqüestros, } \\
\text { detenções arbitrárias e } \\
\text { detenções ilegais ou tortura } \\
\text { em retaliação por suas } \\
\text { atividades profissionais? }\end{array}$ \\
\hline
\end{tabular}




\begin{tabular}{|c|c|c|c|}
\hline & & $\begin{array}{l}\text { Os jornalistas enfrentam } \\
\text { represálias sob a forma de } \\
\text { falsas acusações crimi- } \\
\text { nais sem ligação explícita } \\
\text { ao seu trabalho, como } \\
\text { posse de armas, posse de } \\
\text { drogas ou evasão fiscal? }\end{array}$ & $\begin{array}{l}\text { Os jornalistas enfrentam } \\
\text { represálias sob a forma de } \\
\text { falsas acusações crimi- } \\
\text { nais sem ligação explícita } \\
\text { ao seu trabalho, como } \\
\text { posse de armas, posse de } \\
\text { drogas ou evasão fiscal? }\end{array}$ \\
\hline $\begin{array}{l}\text { As milícias armadas, } \\
\text { o crime organizado, } \\
\text { grupos insurgentes, } \\
\text { extremistas políticos } \\
\text { ou religiosos ou outras } \\
\text { organizações visam re- } \\
\text { gularmente jornalistas? }\end{array}$ & $\begin{array}{l}\text { As milícias armadas, } \\
\text { o crime organizado, } \\
\text { grupos insurgentes, } \\
\text { extremistas políticos } \\
\text { ou religiosos ou outras } \\
\text { organizações visam re- } \\
\text { gularmente jornalistas? }\end{array}$ & $\begin{array}{l}\text { As milícias armadas, o } \\
\text { crime organizado, grupos } \\
\text { insurgentes, extremistas } \\
\text { políticos ou religiosos ou } \\
\text { outras organizações visam } \\
\text { regularmente jornalistas em } \\
\text { resposta ao seu trabalho? }\end{array}$ & $\begin{array}{l}\text { As milícias armadas, o } \\
\text { crime organizado, grupos } \\
\text { insurgentes, extremistas } \\
\text { políticos ou religiosos ou } \\
\text { outras organizações visam } \\
\text { regularmente jornalistas em } \\
\text { resposta ao seu trabalho? }\end{array}$ \\
\hline $\begin{array}{l}\text { Os jornalistas } \\
\text { fugiram do país ou } \\
\text { se esconderam para } \\
\text { evitar essa ação? }\end{array}$ & $\begin{array}{l}\text { Os jornalistas } \\
\text { fugiram do país ou } \\
\text { se esconderam para } \\
\text { evitar essa ação? }\end{array}$ & $\begin{array}{l}\text { Os jornalistas fugiram do } \\
\text { país ou se esconderam } \\
\text { ou foram exilados para } \\
\text { evitar tais repercussões? }\end{array}$ & $\begin{array}{l}\text { Os jornalistas fugiram do } \\
\text { país ou se esconderam } \\
\text { ou foram exilados para } \\
\text { evitar tais repercussões? }\end{array}$ \\
\hline & & $\begin{array}{l}\text { Os jornalistas sob amea- } \\
\text { ça de atores não estatais } \\
\text { recebem proteção adequada } \\
\text { das autoridades estaduais? }\end{array}$ & $\begin{array}{l}\text { Os jornalistas sob amea- } \\
\text { ça de atores não estatais } \\
\text { recebem proteção adequada } \\
\text { das autoridades estaduais? }\end{array}$ \\
\hline $\begin{array}{l}\text { As empresas de } \\
\text { mídia foram alvo de } \\
\text { ataques físicos ou pelo } \\
\text { confisco ou destruição } \\
\text { de propriedade? }\end{array}$ & $\begin{array}{l}\text { As empresas de } \\
\text { mídia foram alvo de } \\
\text { ataques físicos ou pelo } \\
\text { confisco ou destruição } \\
\text { de propriedade? }\end{array}$ & $\begin{array}{l}\text { As empresas de mídia } \\
\text { foram alvo de ataques } \\
\text { físicos ou pelo confisco ou } \\
\text { destruição de propriedade? }\end{array}$ & $\begin{array}{l}\text { As empresas de mídia foram } \\
\text { alvo de ataques físicos ou } \\
\text { pelo confisco ou destrui- } \\
\text { ção de propriedade? }\end{array}$ \\
\hline & $\begin{array}{l}\text { Há ataques técnicos } \\
\text { em sites de notícias e } \\
\text { informações ou em } \\
\text { importantes canais } \\
\text { online para troca } \\
\text { de informações? }\end{array}$ & $\begin{array}{l}\text { Há ataques técnicos - } \\
\text { como ataques de hackers } \\
\text { ou ataques de negação } \\
\text { de serviço distribuídos } \\
\text { (DDoS) - em sites de } \\
\text { notícias ou em contas de } \\
\text { mídia social que são usadas } \\
\text { para disseminar notícias? }\end{array}$ & $\begin{array}{l}\text { Há ataques técnicos - } \\
\text { como ataques de hackers } \\
\text { ou ataques de negação } \\
\text { de serviço distribuídos } \\
\text { (DDoS) - em sites de notícias } \\
\text { ou em contas de mídia } \\
\text { social que são usadas para } \\
\text { disseminar notícias? }\end{array}$ \\
\hline
\end{tabular}

Tabela 3: A segurança dos profissionais de mídia de acordo com a Freedom House

As mudanças são tanto formais quanto substanciais, já que alguns indicadores foram introduzidos a partir de 2016 e outros foram radicalmente modificados. Essas mudanças refletem a intenção da $\mathrm{FH}$ de refinar o campo de investigação de uma questão tão controversa: portanto, é importante a introdução de um indicador sobre a ameaça aos jornalistas de atores não estatais e a proteção adequada das autoridades estaduais. E também é importante levar em conta a questão do "jornalismo embutido" em zonas perigosas. No entanto, essas modificações colocam em questão a comparabilidade dos dados ao longo do tempo, bem como a validade e confiabilidade do instrumento. De fato, a introdução de duas notas para as perguntas na versão 2017 revela uma possível dificuldade da equipe de pesquisa em detectar o problema.

Embora trabalhem para refinar seus instrumentos, tanto a $\mathrm{FH}$ quanto a RSF ainda estão distantes do uso de descritores mais estritos da profissão jornalística, como os usados pela própria Unesco. Tomando como referência a decisão adotada pelo Conselho do Programa Internacional para o Desenvolvimento da Comunicação (IPDC) em 2014 e definida nos Indicadores de Segurança dos Jornalistas: Nível Nacional, considera-se um "jornalista" e, portanto, unidades de análise para o presente artigo, "jornalistas, 
profissionais da mídia e produtores de mídias sociais que geram um volume significativo de atividade jornalística de interesse público" (Unesco, 2013, p. 2):

jornalistas são pessoas que observam, descrevem, documentam e analisam eventos e documentam e analisam declarações, políticas e qualquer proposta que possa afetar a sociedade, a fim de sistematizar essas informações e reunir fatos e análises para informar os setores da sociedade ou da sociedade como um todo. (Unesco, 2012, p. 3)

Os especialistas escolhidos pela $\mathrm{FH}$ analisam os resultados de cada indicador e questionam e categorizam os países em três grandes rótulos no status de país de liberdade de imprensa: "livre", "parcialmente livre" ou "não livre".

Dos 199 países e territórios avaliados para 2016, um total de 61 (31\%) foram classificados como Gratuitos, 72 (36\%) foram classificados como Parcialmente Livres e 66 (33\%) foram classificados como Não Livres. No caso dos Estados latino-americanos estudados, em 2017, quatro deles foram considerados "não livres" (Cuba, com uma pontuação de 91, Honduras, 66, México, 64 e Venezuela, 81) e os demais foram divididos em "parcialmente livre" (Argentina, 46; Bolívia, 53; Brasil, 47; Colômbia, 57; El Salvador, 41; Guatemala, 58; Nicarágua, 55; Panamá, 41; Peru, 42 e República Dominicana, 42), enquanto três foram considerado "livre" (Chile, 29; Costa Rica, 16 e Uruguai, 24) (Tabela 4).

\begin{tabular}{|c|c|c|c|c|c|}
\hline & $\begin{array}{l}\text { ESTATUTO DE } \\
\text { LIBERDADE DE } \\
\text { IMPRENSA }\end{array}$ & $\begin{array}{c}\text { ÍNDICE DE } \\
\text { LIBERDADE DE } \\
\text { LIBERDADE } \\
\text { (0-100 POINTS) }\end{array}$ & $\begin{array}{l}\text { AMBIENTE } \\
\text { JuRÍDICO } \\
\text { (0-30 POINTS) }\end{array}$ & $\begin{array}{c}\text { Ambiente } \\
\text { POLITICo } \\
(0-40)\end{array}$ & $\begin{array}{c}\text { AMBIENTE } \\
\text { ECONÔMICO } \\
(0-30=\end{array}$ \\
\hline Argentina & Parcialmente livre & 46 & 13 & 18 & 15 \\
\hline Bolivia & Parcialmente libre & 53 & 16 & 23 & 14 \\
\hline Brasil & Parcialmente livre & 47 & 14 & 22 & 11 \\
\hline Chile & Livre & 29 & 8 & 13 & 8 \\
\hline Colombia & Parcialmente livre & 57 & 13 & 26 & 18 \\
\hline Costa Rica & Livre & 16 & 4 & 6 & 6 \\
\hline Cuba & Não livre & 91 & 28 & 35 & 28 \\
\hline Ecuador & Não livre & 66 & 23 & 27 & 16 \\
\hline El Salvador & Parcialmente livre & 41 & 10 & 18 & 13 \\
\hline Guatemala & Parcialmente livre & 58 & 18 & 23 & 17 \\
\hline Honduras & Não livre & 66 & 18 & 33 & 15 \\
\hline Mexico & Não livre & 64 & 19 & 31 & 14 \\
\hline Nicaragua & Parcialmente livre & 55 & 14 & 24 & 17 \\
\hline Panamá & Parcialmente livre & 41 & 17 & 15 & 9 \\
\hline Paraguai & Parcialmente livre & 59 & 16 & 24 & 19 \\
\hline Peru & Parcialmente livre & 45 & 14 & 19 & 12 \\
\hline Republica Dominicana & Parcialmente livre & 42 & 8 & 21 & 13 \\
\hline Uruguai & Livre & 24 & 6 & 10 & 8 \\
\hline Venezuela & Não livre & 81 & 26 & 31 & 24 \\
\hline
\end{tabular}


O padrão de violência extrema contra jornalistas em vários países da América Latina continuou inabalável em 2016 (FH, 2017b). Brasil, Colômbia, Honduras e México permanecem entre os lugares mais perigosos do mundo para os jornalistas, e todos enfrentam desafios constantes na investigação e julgamento de tais crimes. O número de assassinatos no México aumentou, de acordo com algumas fontes, especialmente para repórteres que cobrem abusos policiais, tráfico de drogas e corrupção governamental. Embora El Salvador tenha tradicionalmente sofrido menos violência contra jornalistas, apesar da alta taxa geral de homicídios, a intimidação da mídia também aumentou lá. Mecanismos de proteção foram implantados em vários países, mas sua eficácia ainda é limitada por problemas como rivalidades burocráticas, financiamento insuficiente e falta de treinamento (Freedom House, 2017b, p. 21).

\section{Conclusões}

As análises da liberdade de imprensa no mundo e na América Latina em geral são extremamente complexas e merecem uma análise detalhada dos instrumentos que usamos para medi-los. As classificações da Casa da Liberdade e Repórteres sem Fronteiras têm sido tradicionalmente usadas para representar a situação de diferentes países nesta área, mas apresentam sérios problemas metodológicos.

Em primeiro lugar, a presente investigação permitiu afirmar que os indicadores sofrem de deficiências que dificultam a caracterização de realidades concretas, como as da região latino-americana, caracterizadas por um alto grau de violência em determinados países e com diferentes dimensões sociais e sociais. sistemas democráticos de direito.

Nesse sentido, tanto a RSF como a FH penalizam o aparato regulatório do Estado para proteger os direitos dos cidadãos e tornar invisível o trabalho dos latino-americanos em transcender de meros agentes passivos a agentes ativos de comunicação, beneficiando empresas privadas em suas pontuações.

Embora o RSF e o FH partam da visão universal dos direitos humanos em geral e da liberdade de imprensa em particular, eles o reduzem ao livre mercado e, com isso, diminuem a própria idiossincrasia dos direitos fundamentais.

Traduzido por Lenina Vernucci da Silva

\section{REFERÊNCIAS BIBLIOGRÁFICAS}

Banda, F. (2011). What are we measuring? A critical review of media development assessment tools. In M.E. Price, S. Abbott \& L. Morgan L (Eds.), Measures of press freedom and media contributions to development. evaluating the evaluators (pp. 89-107). Nova lorque: Peter Lang.

Badran M. (2017). Violence against journalists: suppressing media freedom. In M. Friedrichsen \& Y. Kamalipour (Eds.), Digital transformation in journalism and news media. Media business and innovation (pp. 417-427). Cham, Suíça: Springer.

Becker, J. (2003). Review article: keeping track of press freedom. European Journal of Communication, 18(1), 107-112. 
Becker, L. B., Vlad, T. \& Nusser, N. (2007). An evaluation of press freedom indicators. The International Communication Gazette, 69(1), 5-28.

Brunetti A. \& Weder B. (2003). A free press is bad news for corruption. Journal of Public Economics, 87, 1801-24.

Burgess, J. (2010). Evaluating the evaluators: media freedom indexes and what they measure. Washington, D.C.: Center for International Media Assistance at the National Endowment for Democracy.

Chomsky, N. \& Herman, E. S. (1988). Manufacturing consent. The political economy of the mass-media. Nova lorque: Pantheon Books.

Comité para la Protección de los Periodistas (CPJ) (2017). Sin Excusa: México debe quebrar el ciclo de impunidad en asesinatos de periodistas. Cidade do México: CPJ.

Dahl, R. A. (2003). How democratic is the American constitution? Yale: Yale University Press.

Díaz Nosty, B. \& de Frutos García, R. (2017). Asesinatos, hostigamientos y desapariciones. La realidad de los periodistas latinoamericanos en el s. XXI. Revista Latina de Comunicación Social, 72, 1.418-1.434.

Díaz Nosty, B. (2016a). Periodismo muerto. Más de mil periodistas asesinados en América Latina (1970-2015). Cidade do México: Planeta Editorial.

Díaz Nosty, B. (2016b). Medio siglo de atentados contra periodistas. Infoamérica. Revista Iberoamericana de Comunicación, 10, 87-113.

Freille S., Haque M. E. \& Kneller R. (2007). A contribution to the empirics of press freedom and corruption. European Journal of Political Economy, 23(4), 838-862.

Freedom House (2012). Checklist of methodology questions 2012. Retirado de www.freedomhouse.org

Freedom House (2017a). Freedom of the press 2017 methodology. Retirado de https://www.ifex.org/ international/2017/11/17/un-resolutions-safety- journalists/https://freedomhouse.org/report/ freedom-press-2017-methodology.

Freedom House (2017b). Freedom of the press. Press freedom's dark horizon. Retirado de https://freedomhouse. org/sites/default/files/FOTP_2017_booklet_FINAL_April28.pdf

Frutos, R. (2014). Indicadores mediáticos: análisis crítico de los modelos de evaluación internacional. Tese de doutoramento, Universidade de Málaga, Málaga, Espanha.

Giannone D. (2010). Political and ideological aspects in the measurement of democracy: the Freedom House Case. Democratization 17(1), 68-97.

Giannone, D. (2014). The political and ideological dimension of the measurement of freedom of information. Assessing the interplay between neoliberalism and the Freedom of the Press Index. International Communication Gazette, 76(6), 505-527.

Giannone, D. \& De Frutos, R. (2016). Measuring freedom of information: issues and opportunities from an expert survey. International Journal of Communication, 10, 589-619.

González de Bustamante C. \& Relly J. E. (2014). Journalism in times of violence: social media use by US and Mexican journalists working in northern Mexico. Digital Journalism, 2, 507-523.

González de Bustamante, C. \& Relly J. E. (2016). Professionalism under threat of violence: journalism, reflexivity, and the potential for collective professional autonomy in northern Mexico. Journalism Studies, 17, 684-702. 
Gunther R. \& Mughan A. (Eds) (2000). Democracy and the media: a comparative perspective. Cambridge: Cambridge University Press.

Hallin D. C. \& Mancini P. (2012). Comparing media systems beyond the western world. Nova lorque: Cambridge University Press.

Holtz-Bacha C. (2011). Freedom of the press: is a worldwide comparison possible and what is it good for? In M. E. Price, S. Abbott \& L. Morgan (Eds.), Measures of press freedom and media contributions to development. Evaluating the evaluators (129-143). Nova lorque: Peter Lang.

Hughes, S. \& Márquez-Ramírez, M. (2017). Examining the practices that mexican journalists employ to reduce risk in a context of violence. International Journal of Communication, 11(23) 499-521.

Hughes S., Mellado C., Arroyave J., Benitez J. L., de Beer A., Garcés M. \& Márquez-IFEX (2017). How can UN resolutions make it safer to be a journalist? Retirado de https://www.ifex.org/international/2017/11/17/ un-resolutions-safety- journalists

Karlekar Deutsch K. \& Radsch C. (2012). Adapting concepts of media freedom to a changing media environment: incorporating new media and citizen journalism into the Freedom of the Press Index. ESSACHESS. Journal for Communication Studies 5(9), 13-22.

Kaufmann D. (2005). Human rights and governance: the empirical challenge. InP. Alston \& M. Robinson (Eds.), Human Rights and Development: Towards Mutual Reinforcement (pp. 352-402). Nova lorque: Oxford University Press,

McQuail, D. (2000). McQuail's mass communication theory. Londres: Sage.

Mirowski, P. (2011). Science-mart. Privatizing American science. Cambridge: Harvard University Press.

Norris P. (2006). The role of the free press in promoting democratization, good governance, and human development. In Unesco meeting on World Press Freedom Day: Media, Development, and Poverty Eradication, Colombo, Sri Lanka, 1-2 May.

Ramírez M. (2017). Expanding influences research to insecure democracies: how violence, public insecurity, economic inequality and uneven democratic performance shape journalists' perceived work environments. Journalism Studies, 18, 645-665.

Relly J. E. \& González de Bustamante, C. (2017). Global and domestic networks advancing prospects for institutional and social change: the collective action response to violence against journalists. The International Journal of Press/Politics, 19, 108-131.

Relly J. E. \& González de Bustamante, C. (2014). Silencing Mexico: a study of influences on journalists in the northern states. The International Journal of Press/Politics, 19, 108-131.

Reporters without Borders (RWB) (2017). Clasificación de la libertad de prensa en el mundo. Retirado de https://www.rsf-es.org/grandes-citas/clasificacion-por-paises/

Sapiezynska, E. \& Lagos, C. (2016). Media freedom indexes in democracies: a critical perspective through the cases of Poland and Chile. International Journal of Communication, 10, 549-570.

Scoble H. M. \& Wiseberg L. S. (1981). Problems of comparative research on human rights". In V. P. Nanda, J. R. Scarritt \& G. W. Jr Shepherd (Eds.), Global human rights: public policies, comparative measures, and NGO strategies (pp. 147-17). Boulder, CO: Westview Press.

Siebert F. R., Peterson T. \& Schramm W. (1956). Four theories of the press. Urbana: University of Illinois Press. 
Sobel R. S., Dutta N. \& Roy S. (2011). Beyond borders: is media freedom contagious? In M. E. Price, S. Abbott $\&$ L. Morgan (Eds.), Measures of press freedom and media contributions to development. Evaluating the evaluators (pp. 307-320). Nova lorque: Peter Lang.

Tran H., Mahmood R., Du, Y. \& Khrapavitski A. (2011). Linking measures of global press freedom to development and culture: implications from a comparative analysis. International Journal of Communication, 5, 170-191.

Unesco (2012). UN plan of action on the safety of journalists and the issue of impunity. Retirado de http:// www.unesco.org/new/fileadmin/MULTIMEDIA/HQ/CI/CI/pdf/official_documents/UN-Plan-on-SafetyJournalists_EN_UN-Logo.pdf

Unesco (2013). Journalists' safety indicators:national level. Based on the Unesco's media development indicators. Retirado de http://www.unesco.org/fileadmin/MULTIMEDIA/HQ/Cl/Cl/pdf/official_documents/ Journalists_Safety_Indicators_National_Level.pdf

Unesco (2016). Time to break the cycle of violence against journalists. Highlights from the UNESCO DirectorGeneral'S 2016 report on safety of journalists and the danger of impunity. Retirado de https://en.unesco. org/sites/default/files/unesco_report_english_rgb.pdf

Unesco \& Reporters Without Borders (2013). Safety guide for journalists. A handbook for reporters in high-risk environments. Retirado de http://unesdoc.unesco.org/images/0024/002439/243988s.pdf

United Nations (2016, 10 de fevereiro). La seguridad de las periodistas y la questión de la impunidad. Resolución 70/162. Retirado de http://www.un.org/es/comun/docs/?symbol=A/RES/70/162

United Nations (2017a). Multi-stakeholder consultation on strengthening the implementation of the UN plan of action on the safety of journalists and the issue of impunity. Retirado de https://en.unesco.org/sites/ default/files/concept_note_multi-stakeholder_consultation_en.pdf

United Nations (2017b, agosto). La seguridad de las periodistas y la cuestión de la impunidad. Informe del Secretario General de Naciones Unidas.

United Nations Development Programme (UNDP) (2004). Governance indicators: a users' guide. Retirado de https://tinyurl.com/79dhnfz

Van Belle, D. A. (1997). Press freedom and the democratic peace. Journal of Peace Research, 34(4), 405-414.

Voltmer K. (2013). The media in transitional democracies. Cambridge: Polity Press.

\section{NOTAS BIOGRÁFICAS}

Ruth de Frutos é Coordenadora da Cátedra Unesco em Comunicação na Universidade de Málaga, Espanha.

E-mail: ruth.defrutos@uma.es

Morada: Universidade de Málaga, Málaga, 2907 Espanha

Diego Giannone é Professor do Departamento de Ciências Políticas "Jean Monnet" da Università della Campania “Luigi Vanvitelli”, Itália

E-mail: diego.GIANNONE@unicampania.it

Morada: Departamento de Ciência Política "Jean Monnet" da Università della Campania “Luigi Vanvitelli”. Viale Ellittico, 31-81100 Caserta, Itália 


\section{* Submetido: 30.11 .2017}

* Aceite: 15.03 .2018 